\title{
Cholera in the Era of COVID-19 Pandemic: A Worrying Trend in Africa?
}

\author{
Oloche Owoicho ${ }^{1,2,3 *}$, Priscilla Abechi ${ }^{4}$ and Charles Ochieng' Olwal ${ }^{1,3}$ \\ ${ }^{1}$ West African Centre for Cell Biology of Infectious Pathogens WACCBIP), University of Ghana, Accra, Ghana, ${ }^{2}$ Department of \\ Biological Sciences, Benue State University, Makurdi, Nigeria, ${ }^{3}$ Department of Biochemistry, Cell and Molecular Biology, College \\ of Basic and Applied Sciences, University of Ghana, Accra, Ghana, ${ }^{4}$ African Centre of Excellence for Genomics of Infectious \\ Diseases, Redeemer's University, Ede, Nigeria
}

Keywords: COVID-19 pandemic, SARS-CoV-2, cholera, Vibrio cholerae, WASH

The IJPH series "Young Researcher Editorial" is a training project of the Swiss School of Public Health.

Since 2019 the Coronavirus Disease 2019 (COVID-2019) pandemic has caused a massive increase in mortality and strained health care facilities around the world. In Africa COVID-19 has caused more than 100,000 associated deaths [1] and slowed the fight against deadly infectious diseases like malaria, tuberculosis, HIV/AIDS and neglected tropical diseases [2, 3]. It may also have slowed progress against cholera.

Amid the COVID-19 pandemic, Burundi, Benin, Cameroon, Democratic Republic of Congo, Ethiopia, Kenya, Mozambique, Nigeria, Togo and Uganda have reported cholera outbreaks [4, 5]. In non-pandemic years, there are about 2.9 million cholera cases and 95,000 associated annual deaths in 69 cholera-endemic countries, most of which are within the subSaharan Africa [7]. Cholera is an acute watery diarrhea caused by toxigenic strains of Vibrio cholerae, particularly serogroups $\mathrm{O} 1$ and $\mathrm{O} 139$, characterized by excessive dehydration and a high fatality rate [6]. It is acquired fecal-orally via contaminated food and water. Contaminated drinking water, poor sanitation and hygiene, fragile health care systems, humanitarian crises and hydroclimatic factors account for the disproportionate burden of cholera in sub-Saharan Africa [8, 9].

In 2019, 16 African countries reported 55,087 cholera cases, with a case fatality rate (CFR) of $1.6 \%$ - a considerable decrease from the $2.0 \%$ reported in 2018 [10]. Cholera CFR increased in 2020; for example, in Central and West Africa, CFR rose from 1.8\% in 2019 to $2.1 \%$ in 2020 [11]. But the number of cholera cases decreased from 34,957 to 23,628 in the same two sub-regions [11]. At the country level, from 2019 to 2020 , cholera CFR rose by $2.2 \%$ in Benin, $0.4 \%$ in Cameroon, 1.2\% in Liberia, and 3.5\% in Nigeria [11]. In Nigeria, the 2020 outbreak extended into 2021, comprising 266 suspected cases from geographically distinct communities, and reported a CFR of $12.0 \%$ from December 2020 to January 2021 [12]. Collectively, these statistics show that meeting the Global Task Force on Cholera Control's 2030 target of reducing cholera deaths by $90 \%$ will require stepping up the fight against cholera in sub-Saharan Africa, even amid the pandemic.

The pandemic may have a negative effect on key cholera control components like surveillance, a key measure against cholera outbreak and associated mortality. Effective surveillance is needed to detect $V$. cholerae early in clinical, environmental, or food samples. When health workers and funds are reassigned to fight the COVID-19 pandemic, fewer health workers and less funding may be available for cholera surveillance, especially in resource-limited settings like sub-Saharan Africa. Since CFR is a function of disease cases, the increased cholera CFR in 2020 in Central and West Africa may have resulted from reduced surveillance, more severe cholera, and the higher number of cholera-related deaths.

Int I Public Health doi: 10.3389/ijph.2021.1604030 
COVID-19 may also have decreased health promotion activities that mitigate cholera outbreaks. Health promotion complements other cholera control and/or prevention factors like access to potable water, sanitation, and hygiene (WASH). COVID-19 restrictions on transportation and assembly during the pandemic may hinder community-oriented health education and promotion activities that could help control cholera outbreaks. Though the increase in hand washing and/or sanitization in response to the COVID-19 pandemic is expected decrease food- and waterborne infections, cholera statistics from sub-Saharan African countries do not seem to support this hypothesis. We think that limited access to clean water and poor waste disposal in many rural areas and peri-urban slums in sub-Saharan Africa makes it hard to implement hand hygiene effectively.

Finally, COVID-19 may reduce the rate of vaccination against cholera in sub-Saharan Africa. Sustained cholera control in lowand middle-income countries (LMICs) depends on administering oral cholera vaccines but routine vaccinations against infectious diseases, including cholera, were disrupted in many LMICs in the early phase of the COVID-19 pandemic [13].

Although the statistics we cited were mainly gathered from the Central and West African regions, the situation is similar throughout sub-Saharan Africa [14]. While this editorial was under review, Hassan and Nellums [15] provided evidence that supports the view that cholera is a threat in most subSaharan African countries. Specifically, they highlighted the threat of cholera outbreak in Ethiopia and Sudan, where ongoing humanitarian crises and COVID-19 compounded the difficulties of stemming the cholera epidemic [15]. There is need for more deliberate efforts to prevent and control cholera in sub-Saharan Africa, during and beyond the pandemic.

To end cholera in sub-Saharan Africa, nations should consider investing in infrastructure like potable water supplies, especially in rural communities and peri-urban slums, since they are hot-

\section{REFERENCES}

1. Africa, CDC. Coronavirus Disease 2019 (COVID-19) - Latest Updates on the COVID-19 Crisis from Africa CDC (2021). Available at: https://africacdc.org/ covid-19/(Accessed March 15, 2021).

2. Nghochuzie, NN, Olwal, CO, Udoakang, AJ, Amenga-Etego, LN-K, and Amambua-Ngwa, A. Pausing the Fight against Malaria to Combat the COVID-19 Pandemic in Africa: Is the Future of Malaria Bleak? Front Microbiol (2020). 11:1476. doi:10.3389/ fmicb.2020.01476

3. Molyneux, DH, Aboe, A, Isiyaku, S, and Bush, S. COVID-19 and Neglected Tropical Diseases in Africa: Impacts, Interactions, Consequences. Int Health (2020). 12:367-72. doi:10.1093/inthealth/ihaa040

4. European Centre for Disease Prevention and Control. Cholera Worldwide Overview (2021). Available at: https://www.ecdc.europa.eu/en/all-topicsz/cholera/surveillance-and-disease-data/cholera-monthly (Accessed March 18, 2021).

5. World Health Organization Africa Regional Office. Weekly Bulletin on Outbreaks and Other Emergencies (2020). Available at: https://apps.who. int/iris/bitstream/handle/10665/332993/OEW27-290505072020.pdf (Accessed March 18, 2021). spots for cholera outbreaks. Health care systems in sub-Saharan Africa should be strengthened through capacity building to ensure there are enough trained local health care workers. Though the scale of the COVID-19 pandemic exceeds that of most infectious diseases in sub-Saharan Africa, countries where cholera is endemic still need to allocate financial resources and human capital to prevent outbreaks.

\section{AUTHOR CONTRIBUTIONS}

All authors listed have made a substantial, direct, and intellectual contribution to the work and approved it for publication.

\section{FUNDING}

$\mathrm{OO}$ and $\mathrm{COO}$ were supported by WACCBIP-ACE PhD fellowship (ACE02-WACCBIP: Awandare) and a DELTAS Africa grant (DEL-15-007: Awandare). The DELTAS Africa Initiative is an independent funding scheme of the African Academy of Sciences (AAS)'s Alliance for Accelerating Excellence in Science in Africa (AESA) and supported by the New Partnership for Africa's Development Planning and Coordinating Agency (NEPAD Agency) with funding from the Wellcome Trust (107755/Z/15/Z to Awandare) and the UK government. The views expressed in this publication are those of the author(s) and not necessarily those of AAS, NEPAD Agency, Wellcome Trust or the UK government.

\section{CONFLICT OF INTEREST}

The authors declare that the research was conducted in the absence of any commercial or financial relationships that could be construed as a potential conflict of interest.

6. Clemens, JD, Nair, GB, Ahmed, T, Qadri, F, and Holmgren, J. Cholera. Lancet (2017). 390:1539-49. doi:10.1016/S0140-6736(17)30559-7

7. Ali, M, Nelson, AR, Lopez, AL, and Sack, DA. Updated Global burden of Cholera in Endemic Countries. Plos Negl Trop Dis (2015). 9:e0003832. doi:10. 1371/journal.pntd.0003832

8. Gwenzi, W, and Sanganyado, E. Recurrent Cholera Outbreaks in Subsaharan Africa: Moving beyond Epidemiology to Understand the Environmental Reservoirs and Drivers. Challenges (2019). 10:1. doi:10. 3390/challe10010001

9. Elimian, KO, Mezue, S, Musah, A, Oyebanji, O, Fall, IS, Yennan, S, et al. What Are the Drivers of Recurrent Cholera Transmission in Nigeria? Evidence from a Scoping Review. BMC Public Health (2020). 20:432. doi:10.1186/ s12889-020-08521-y

10. World Health Organization. Weekly Epidemiological Record Cholera. Cholera (2019). 37:441-8.

11. ReliefWeb. Cholera Outbreaks in Central and West Africa: 2020 Regional Update - Week 1-53 [EN/FR] - Democratic Republic of the Congo (2020). Available at: https://reliefweb.int/report/democratic-republic-congo/choleraoutbreaks-central-and-west-africa-2020-regional-update-6 (Accessed February 7, 2021).

12. World Health Organization Africa Regional Office. Weekly Bulletin on Outbreaks and Other Emergencies (2021). Available at: https://apps.who. 
int/iris/bitstream/handle/10665/338891/OEW04-1824012021.pdf (Accessed March 16, 2021).

13. Hossain, MM, Abdulla, F, Karimuzzaman, M, and Rahman, A. Routine Vaccination Disruption in Low-Income Countries: An Impact of COVID19 Pandemic. Asia Pac J Public Health (2020). 32:509-10. doi:10.1177/ 1010539520957808

14. Taremwa, A. Fighting a Cholera Outbreak in the Middle of a COVID-19 Pandemic: Moroto's story of Resilience (2020). Available at: https://www. uniceforg/uganda/stories/fighting-cholera-outbreak-middle-covid-19-pandemic (Accessed April 7, 2021).
15. Hassan, OB, and Nellums, LB. Cholera during COVID-19: The Forgotten Threat for Forcibly Displaced Populations. EClinicalMedicine (2021). 32: 100753. doi:10.1016/j.eclinm.2021.100753

Copyright $\odot 2021$ Owoicho, Abechi and Olwal. This is an open-access article distributed under the terms of the Creative Commons Attribution License (CC BY). The use, distribution or reproduction in other forums is permitted, provided the original author(s) and the copyright owner(s) are credited and that the original publication in this journal is cited, in accordance with accepted academic practice. No use, distribution or reproduction is permitted which does not comply with these terms. 